\title{
Chain dimension of polyampholytes in solution and immobilized brush states
}

\begin{abstract}
Moriya Kikuchi $^{1}$, Yuki Terayama ${ }^{2}$, Tatsuya Ishikawa ${ }^{2}$, Taiki Hoshino ${ }^{1}$, Motoyasu Kobayashi ${ }^{1}$, Hiroki Ogawa $^{3}$, Hiroyasu Masunaga ${ }^{3}$, Jun-ichiro Koike ${ }^{4}$, Misao Horigome ${ }^{4}$, Kazuhiko Ishihara ${ }^{5}$ and Atsushi Takahara ${ }^{1,2,6}$

The dimensions and intermolecular interactions of surface-grafted and unbound, free polyampholytes, poly[3-( $\mathrm{N}-2$ methacryloyloxyethyl- $N, N$-dimethyl) ammonatopropanesulfonate] (PMAPS) and poly(2-methacryloyloxyethyl phosphorylcholine) (PMPC), were estimated in an aqueous $\mathrm{NaCl}$ solution over a wide range of salt concentrations $\left(C_{\mathrm{s}}\right)$. The free PMAPS and PMPC fractionated by a recycling preparative size-exclusion chromatography system were characterized in aqueous $\mathrm{NaCl}$ solutions for $C_{\mathrm{s}}$ over a range from 0 to $5.0 \mathrm{~m}$ by static light scattering and dynamic light scattering (DLS) measurements. The hydrodynamic radius $\left(R_{\mathrm{H}}\right)$ and the concentration coefficient of the diffusion coefficient $\left(k_{\mathrm{D}}\right)$ for PMPC were independent of $C_{\mathrm{s}}$, whereas those for PMAPS were strongly dependent on $C_{\mathrm{s}}$. Monodisperse silica nanoparticles immobilized with PMAPS (SiNP-PMAPS) and PMPC (SiNP-PMPC) by surface-initiated atom transfer radical polymerization were characterized in aqueous $\mathrm{NaCl}$ solutions for $C_{\mathrm{s}}$ over a range from 0 to $5.0 \mathrm{~m}$ by DLS and synchrotron radiation small-angle X-ray scattering (SAXS) measurements. The SAXS profiles from SiNP-PMAPS and SiNP-PMPC solutions were well described by the core-shell model, taking into account interacting self-avoiding chains and assuming a Schulz-distributed core with two fitting parameters.
\end{abstract} Polymer Journal (2012) 44, 121-130; doi:10.1038/pj.2011.116; published online 16 November 2011

Keywords: ionic strength; light scattering; nanoparticle; polyampholytes; polymer brush; SAXS

\section{INTRODUCTION}

Zwitterionic polyelectrolytes that possess both positive and negative charges can be found in certain natural substances with a high molecular weight, such as poly(amino acid)s, proteins, DNA and cell membrane surfaces. These substances form self-assemblies and nanostructures in aqueous media. ${ }^{1}$ Various types of polyelectrolyte brushes have been prepared to modify solid surfaces to achieve biocompatibility, switchable wettability and low friction under aqueous conditions.

For example, poly(3-(N-2-methacryloyl-oxyethyl- $N, N$-dimethyl) ammonatopropanesulfonate) (PMAPS) and poly(2-methacryloyloxyethyl phosphorylcholine) (PMPC) are insoluble and soluble in deionized water at room temperature, respectively. PMAPS is soluble in a solution at a sufficiently higher temperature than the upper critical solubility temperature, ${ }^{2}$ as well as in an aqueous salt solution because of the strong attractive intermolecular and intramolecular electrostatic interaction between ammonium cations and sulfonyl anions. Huck and co-workers ${ }^{3}$ prepared a PMAPS brush on gold surfaces by surface-initiated atom transfer radical polymerization, in which they showed that surface wettability changed from hydrophilic to hydrophobic because of the strong interchain and intrachain associations at the upper critical solubility temperature accompanying a change in the thickness of the brushes in an aqueous medium. In addition, excellent lubrication in an aqueous medium was observed on the surface of a PMPC brush. ${ }^{4,5}$ The PMPC brush has attracted a great deal of interest because of its excellent biocompatibility ${ }^{6,7}$ and characteristics such as its antifouling behavior. ${ }^{8}$ To understand the mechanism responsible for the excellent biocompatibility and lubrication behavior, it is very important to examine the swollen structure, the conformation of polyelectrolyte brushes in an aqueous solution and the dependence on ionic strength in comparison with the solution properties of unbound, free polyelectrolytes.

In general, high-density polymer brush chains immersed in a good solvent are extended in a perpendicular direction from a substrate because of the osmotic pressure generated by the excluded volume effect. ${ }^{9}$ Tsujii et al. carried out force curve measurements on a swollen poly(methyl methacrylate) brush on a silicon wafer. They used a silica probe for atomic force microscopy and determined the equilibrium thickness of the brush. The thickness was three times as large as the scaled dry thickness. ${ }^{10}$ However, it is very difficult to precisely determine the swollen thickness of polyelectrolyte brushes in an aqueous solution. In the case of atomic force microscopy, strong electrostatic attractive or repulsive interactions occur between the polyelectrolyte surface and the probe in an aqueous solution with low ionic strength.

${ }^{1}$ Japan Science and Technology Agency, ERATO, Takahara Soft Interfaces Project, Fukuoka, Japan; ${ }^{2}$ Graduate School of Engineering, Kyushu University, Fukuoka, Japan; ${ }^{3}$ Japan Synchrotron Radiation Research Institute/SPring-8, Hyogo, Japan; ${ }^{4}$ DIC Cooperation, Chiba, Japan; ${ }^{5}$ Department of Materials Engineering, The University of Tokyo, Tokyo, Japan and ${ }^{6}$ Institute for Materials Chemistry and Engineering, Kyushu University, Fukuoka, Japan

Correspondence: Professor A Takahara, Institute for Materials Chemistry and Engineering, Kyushu University, 744 Motooka, Nishi-ku, Fukuoka 819-0395, Japan.

E-mail: takahara@cstf.kyushu-u.ac.jp

Received 9 April 2011; revised 7 September 2011; accepted 9 September 2011; published online 16 November 2011 
Previously, neutron reflectometry at the polyelectrolyte brushes/ deuterium oxide interface was used to characterize the swollen structure of PMAPS ${ }^{11,12}$ and PMPC ${ }^{13}$ brushes. However, the neutron scattering length density profile provided only an ambiguous estimate of the internal structure of the brushes in an aqueous solution with a large molecular weight distribution (MWD) because the average height of the brush increases with polydispersity, whereas the average stretching in the brush decreases. ${ }^{14}$

In most studies, polyelectrolyte brushes are prepared either by adsorption of block copolymers consisting of a hydrophobic and a polyelectrolyte block on latex particles ${ }^{15}$ or by surface-initiated polymerization of ionic monomers from hydrophobic polymer latex particles. Polzer et al. ${ }^{16}$ prepared a PMAPS brush shell on a colloidal particle consisting of a polystyrene gel core, the structure of which was confirmed by cryogenic transmission electron microscopy and dynamic light scattering (DLS) in aqueous $\mathrm{NaCl}$ and $\mathrm{KCl}$ solutions. However, the interfacial width of the core and shell was unclear, especially in an aqueous salt solution because of the possibility that the polystyrene core might be strained by swollen PMAPS brush chains due to high osmotic pressure. Matsuda et al. ${ }^{17,18}$ prepared surface-grafted PMPC on silica nanoparticles by surface-initiated atom transfer radical polymerization to measure DLS in aqueous $\mathrm{NaCl}$ solutions. Interestingly, they found that the hydrodynamic radius $\left(R_{\mathrm{H}}\right)$ and the second virial coefficient $\left(A_{2}\right)$ of PMPC were independent of the concentration of $\mathrm{NaCl}(0-0.5 \mathrm{M})$, whereas both the $R_{\mathrm{H}}$ and the $A_{2}$ of typical polyampholytes depended strongly on the ionic strength. Unfortunately, there is still a lack of studies at a salt concentration much higher than $1.0 \mathrm{M}$; such studies are of utmost importance to the full understanding of electrostatic excluded-volume and chain stiffness effects. To the best of our knowledge, previous experimental work on the polyelectrolyte brush state is limited to chain dimension in an aqueous solution. In this paper, we will focus on the dependence of the ionic strength of surface-grafted zwitterionic polyelectrolyte chains attached to the solid on the chain conformation.

In the case of free PMAPS, the dependence of $R_{\mathrm{H}}$ and intrinsic viscosity of poly(sulfobetaine)s on ionic strength have been well studied by DLS and viscometry measurements; ${ }^{2,19-23}$ the unique phase behaviors have been known to depend on salt concentration, ${ }^{19,23,24}$ additive salt ion species, ${ }^{25}$ temperature, ${ }^{2}$ molecular weight and solvent polarity. ${ }^{20,26}$ The $z$-average, mean-square radius of gyration $<S^{2}>_{\mathrm{z}}$ and $A_{2}$ of PMAPS in an aqueous $\mathrm{NaCl}$ solution at $1.0 \mathrm{M}$ and in 2,2,2-trifluoroethanol (TFE) were estimated by Huglin and Radwan, ${ }^{22,27}$ who also determined the intrinsic viscosity of PMAPS in a $\theta$-solvent. With increasing salt concentration in an aqueous solution above the $\theta$-concentration, greater chain dimensions of PMAPS were observed in an aqueous solution because the attractive electrostatic interaction among sulfobetaine groups was neutralized by the screening effect of salt ions. ${ }^{28}$ Kato et al. estimated the $\left\langle S^{2}\right\rangle_{\mathrm{z}}$ and $\theta$-concentration of PMAPS in an aqueous $\mathrm{NaCl}$ solution at $0.060 \mathrm{M}$ with static light scattering (SLS) for polymers with a weight-average molecular weight $\left(\mathrm{M}_{\mathrm{w}}\right)$ in the range of $5.4 \times 10^{4}$ to $5.0 \times 10^{6}$. However, the MWD of polymers was not clarified in their report. Polymers with a broad MWD are unfavorable for the estimation of chain dimensions.

In this study, we prepared a well-defined polyelectrolyte brush by surface-initiated atom transfer radical polymerization of MAPS and MPC monomers from SiNPs with a diameter of $\sim 100 \mathrm{~nm}$. The chain dimensions and intermolecular interactions of surface-grafted and unbound PMAPS and PMPC were estimated in aqueous $\mathrm{NaCl}$ solutions at various salt concentrations $\left(C_{\mathrm{s}}\right)$ from 0 to $5.0 \mathrm{M}$ by SLS,
DLS and synchrotron small-angle X-ray scattering (SAXS). In particular, the effects of salt concentration on the chain conformation of surfacegrafted PMAPS and PMPC chains on SiNPs will be discussed.

\section{EXPERIMENTAL PROCEDURES}

\section{Materials}

Copper (I) bromide (CuBr, Wako Pure Chemicals, Osaka, Japan, 99.9\%) was purified by successive washing with acetic acid and ethanol and then dried under vacuum. 2-(Dimethylamino)ethyl methacrylate (Wako Pure Chemicals, 98\%), 2,2'-dipyridyl (bpy, Wako Pure Chemicals, 99.5\%), 1-ethyl-3-methylimidazolium chloride (EMImCl, Merck, KGaA, Darmstadt, Germany, 98\%) and 1,3-propane sultone (Aldrich, St Louis, MO, USA, 99\%) were used as received. TFE (Tokyo Chemical, 99.0\%) was carefully degassed by a freeze-pump-thaw process before dilution of $\mathrm{CuBr}$ and bpy. MAPS, ${ }^{29} \mathrm{MPC}^{6}$ and tris(2-(dimethy1)aminoethyl) amine $\left(\mathrm{Me}_{6} \mathrm{TREN}\right)^{30}$ were synthesized using previously reported procedures. Deionized water for sample preparation of light scattering and SAXS samples was purified with arium 611UV (Sartorius Stedim Biotech $\mathrm{GmbH}$, Goettingen, Germany, resistivity=18.2 M $\Omega \mathrm{cm}$ ). Silica nanoparticles (SiNPs) with a radius of $\sim 50 \mathrm{~nm}$ dispersed in water (40 wt $\%$ ) were kindly supplied by Nissan Chemical Industries, Tokyo, Japan. The free PMAPS and PMPC were prepared by free radical homopolymerization of corresponding monomer using 2,2'-azobis(isobutyronitrile) as an initiator in TFE at $60^{\circ} \mathrm{C}$ for $24 \mathrm{~h}$. Free polymer samples with a narrow MWD were fractionated by a recycling preparative size-exclusion chromatography system (Japan Analytical Industry, Tokyo, Japan, LC-9104) equipped with an RI detector (JAI RI-7s, Japan) using two columns (JAIGEL GS620-50L, GS320-50L) in an aqueous $\mathrm{NaCl}$ solution at $C_{\mathrm{s}}=0.2 \mathrm{M}$ as an eluent at a flow rate of $20 \mathrm{ml} \mathrm{min}^{-1}$ at room temperature. The $\mathrm{M}_{\mathrm{w}}$ and MWD of the fractionated samples were determined by size-exclusion chromatography measurement using an aqueous $\mathrm{NaCl}$ solution at $C_{s}=0.2 \mathrm{M}$ as an eluent calibrated with a series of corresponding polymers as a standard. ${ }^{12}$ The values of $\mathrm{M}_{\mathrm{w}}$ and $\mathrm{M}_{\mathrm{w}} / \mathrm{M}_{\mathrm{n}}$ of free PMAPS were determined to be $2.47 \times 10^{5} \mathrm{~g} \mathrm{~mol}^{-1}$ and 1.18 , respectively. The values of $\mathrm{M}_{\mathrm{w}}$ and $\mathrm{M}_{\mathrm{w}} / \mathrm{M}_{\mathrm{n}}$ of free PMPC were determined to be $2.34 \times 10^{5} \mathrm{~g} \mathrm{~mol}^{-1}$ and 1.12 , respectively.

\section{Immobilization of the surface initiator}

The surface initiator (2-bromo-2-methyl)propionyloxyhexyltriethoxysilane $(\mathrm{BHE})^{31}$ was synthesized by hydrosilylation of 5-hexenyl 2-bromoisobutylate treated with triethoxysilane in the presence of the Karstedt catalyst. ${ }^{32}$ Immobilization of BHE on an SiNP (SiNP-BHE) was accomplished using a previously reported procedure. ${ }^{17,31}$ A commercially supplied SiNP suspension $(10 \mathrm{ml})$ was collected in a 500-ml round-bottomed flask and was diluted with $100 \mathrm{ml}$ of ethanol. A mixture of ammonia solution $\left(28 \% \mathrm{NH}_{3}\right.$ aqueous solution, $10 \mathrm{ml})$ and ethanol $(180 \mathrm{ml})$ was added dropwise to the SiNP suspension over $3 \mathrm{~h}$ with stirring, and the system was stirred for $2 \mathrm{~h}$ at $40{ }^{\circ} \mathrm{C}$. BHE $(2 \mathrm{~g}, 4.8 \mathrm{mmol})$ diluted with ethanol $(10 \mathrm{ml})$ was added dropwise to the suspension over $15 \mathrm{~min}$, and the reaction mixture was continuously stirred for another $15 \mathrm{~h}$ at $40^{\circ} \mathrm{C}$. SiNP-BHE was then cleaned by consecutive centrifugation and redispersion in ethanol. Finally, the SiNP-BHE suspension in ethanol was solvent exchanged to TFE to obtain a $10 \mathrm{wt} \%$ suspension in TFE.

\section{Surface-initiated atom transfer radical polymerization of MAPS and MPC from SiNP}

Thereafter, MAPS (0.327 mmol), EMImCl $(0.65 \mathrm{~g})$, TFE $(3.4 \mathrm{~g})$ and $10 \mathrm{wt} \%$ SiNP suspension in TFE ( $2.5 \mathrm{~g})$ were loaded into a well-dried glass tube with a stopcock, degassed three times by the freeze-thaw process and flushed with argon. ${ }^{33}$ A copper catalyst solution containing $\mathrm{CuBr}(0.0075 \mathrm{mmol})$ and bpy $(0.015 \mathrm{mmol})$ diluted with degassed TFE was placed into another glass tube and injected into the mixture suspension. The resulting reaction mixture was again degassed by repeated freeze-thaw cycles to remove the oxygen and then subsequently sealed off under reduced pressure. The polymerization reaction was carried out in a stirring oil bath at $60^{\circ} \mathrm{C}$ for $13 \mathrm{~h}$. The reaction was stopped by opening the glass vessel to air at $0{ }^{\circ} \mathrm{C}$. The reaction mixture was poured into methanol, filtered and dried. SiNP-PMAPS was purified by consecutive redis- 
Table 1 Characteristics of SiNP-PMAPS and SiNP-PMPC

\begin{tabular}{lcccrr}
\hline Sample & $M_{\mathrm{n}} \times 10^{-4 \mathrm{a}}\left(\mathrm{g} \mathrm{mol}{ }^{-1}\right)$ & $M_{\mathrm{w}} M_{\mathrm{n}}{ }^{\mathrm{a}}$ & $R_{c}{ }^{\mathrm{b}}(\mathrm{nm})$ & $w^{\mathrm{c}}$ (wt\%) & \multicolumn{1}{c}{$N^{\mathrm{d}}$} \\
\hline PMAPS & 2.38 & 1.27 & 55 & 14.8 & 0.129 \\
PMPC & 2.09 & 1.72 & 56 & 7.1 & 0.066 \\
\hline
\end{tabular}

Abbreviations: PMAPS, poly[3-(N-2-methacryloyloxyethyl- $N, N$-dimethyl) ammonatopropanesulfonate]; PMPC, poly(2-methacryloyloxyethyl phosphorylcholine); SAXS, small-angle X-ray scattering;

$\mathrm{SEC}$, size-exclusion chromatography; SiNP, silica nanoparticle; TGA, thermogravimetric analysis.

a Determined by SEC measurement using an aqueous $\mathrm{NaCl}$ solution at $0.2 \mathrm{~m}$ as an eluent calibrated with a series of corresponding polymers as a standard.

bDetermined by SAXS.

'The weight loss of polymer is measured by TGA.

dThe average number of graft polymer chains per SiNP.

persion in TFE and reprecipitation in methanol to remove the unreacted MAPS and SiNP-BHE and was finally dried under reduced pressure at $60^{\circ} \mathrm{C}$ for $12 \mathrm{~h}$.

Thereafter, MPC $(1.55 \mathrm{mmol}), \mathrm{EMImCl}(0.54 \mathrm{~g})$ TFE $(20 \mathrm{~g})$ and a $10 \mathrm{wt} \%$ SiNP suspension in TFE $(0.5 \mathrm{~g})$ were loaded into a well-dried glass tube with a stopcock, degassed three times by the freeze-thaw process and flushed with argon. A copper catalyst solution containing $\mathrm{CuBr}(0.016 \mathrm{mmol})$ and bpy $(0.032 \mathrm{mmol})$ diluted with degassed TFE was placed in another glass tube and injected into the mixture suspension. The resulting reaction mixture was again degassed by repeated freeze-thaw cycles to remove the oxygen and then subsequently sealed off under reduced pressure. The polymerization reaction was carried out in a stirring oil bath at $60^{\circ} \mathrm{C}$ for $24 \mathrm{~h}$. The reaction was stopped by opening the glass vessel to air at $0{ }^{\circ} \mathrm{C}$. The reaction mixture was cleaned by three cycles of centrifugation and redispersion in methanol to remove the unreacted MPC. Finally, the SiNP-PMPC suspension in methanol was poured into tetrahydrofuran, filtered and dried under reduced pressure at $60^{\circ} \mathrm{C}$ for $12 \mathrm{~h}$.

To determine the $M_{n}$ and $M_{w} / M_{n}$ of the surface-grafted polymer on SiNPs, PMAPS and PMPC chains were cleaved from the surface as follows. SiNPPMAPS and SiNP-PMPC were immersed in a solution mixture of $10 \mathrm{wt} \%$ hydrogen fluoride aqueous solution $(5 \mathrm{ml})$ and an aqueous $\mathrm{NaCl}$ solution at $C_{\mathrm{s}}=0.2 \mathrm{M}(10 \mathrm{ml})$ for 3 days in a plastic vessel and slowly neutralized using a sodium hydrogen carbonate aqueous solution. The resulting solutions were collected in a dialysis membrane tube (Spectra/Por 3, Standard regulated cellulose membrane, $\mathrm{M}_{\mathrm{w}}=3.50 \times 10^{3} \mathrm{~g} \mathrm{~mol}^{-1}$ ) and dialyzed in water to remove inorganic salt ions for 3 days and were freeze dried from aqueous solution. The values of $M_{n}$ and $M_{w} / M_{n}$ of the obtained surface-grafted PMAPS and PMPC on an SiNP were determined by size-exclusion chromatography measurement using an aqueous $\mathrm{NaCl}$ solution at $C_{\mathrm{s}}=0.2 \mathrm{M}$ as an eluent calibrated with a series of corresponding polymers as a standard. The characteristics of SiNPPMAPS and SiNP-PMPC used in this study are listed in Table 1. The values of weight loss measured by thermogravimetric analysis (Perkin-Elmer Pyris TGA) of SiNP-PMAPS and SiNP-PMPC were determined to be 14.8 and $7.1 \mathrm{wt} \%$, respectively.

\section{Measurements}

Both SLS and DLS experiments of the free polymer and surface-grafted polymer on SiNPs in aqueous $\mathrm{NaCl}$ solutions at $25^{\circ} \mathrm{C}$ were carried out at a scattering angle $(\theta)$ ranging from 30 to $150^{\circ}$ using a goniometer system (ALV CGS-3-TAC/LSE-5004, Langen, Germany) using a HeNe laser (wavelength $\lambda=632.8 \mathrm{~nm}$ ) with a power of $22 \mathrm{~mW}$. The Rayleigh ratio at a scattering angle of $\theta=90^{\circ}$ was based on that of pure toluene at a wavelength of $632.8 \mathrm{~nm}$ at $25^{\circ} \mathrm{C} .{ }^{34}$ The autocorrelation function was obtained by pseudo-cross-correlation of the signals from two photomultipliers to suppress noise. The samples for SLS and DLS measurements had four different concentrations in aqueous $\mathrm{NaCl}$ solutions $\left(C_{\mathrm{s}}=0-5.0 \mathrm{M}\right)$ contained in $10-\mathrm{mm}$ diameter quartz cells. The scattering vector $(q)$ was defined as $4 \pi n_{\mathrm{s}} \sin (\theta / 2) / \lambda$, where $n_{\mathrm{s}}$ is the refractive index of the solvent.

The densities of aqueous $\mathrm{NaCl}$ solutions and polymer solutions were measured at $25^{\circ} \mathrm{C}$ using a density meter (Kyoto Electronics Manufacturing DA-505, Kyoto, Japan). The density of an aqueous $\mathrm{NaCl}$ solution at $25^{\circ} \mathrm{C}$ can be expressed by ${ }^{35}$

$$
\rho_{m}=\left(41.873 m-2.0737 m^{3 / 2}-0.6235 m^{2}-0.0257 m^{5 / 2}\right) \times 10^{-3}+\rho_{0},
$$

where $m$ and $\rho_{0}$ are the molal concentration and density $\left(0.99705 \mathrm{~g} \mathrm{~cm}^{-3}\right)$ of pure water, respectively. The value of $m$ is then converted to $C_{\mathrm{s}}(\mathrm{M})$ by

$$
C_{\mathrm{s}}(\mathrm{M})=\frac{\mathrm{m} \rho_{\mathrm{s}}}{10^{3}+\mathrm{mM}} \times 10^{3},
$$

where $M$ is the molecular weight of $\mathrm{NaCl}$. The values of the refractive index $\left(n_{\mathrm{s}}\right)$ for aqueous $\mathrm{NaCl}$ solutions for $C_{\mathrm{s}}$ from 0 to $5.0 \mathrm{M}$ were measured at $25^{\circ} \mathrm{C}$ using a multi-wavelength refractometer (Kyoto Electronics Manufacturing RA-500NW-S, $\lambda=633 \mathrm{~nm}$ ). The value was found to be expressed by

$$
n_{\mathrm{s}}=\left(-6.65 C_{\mathrm{s}}^{3}-188 C_{\mathrm{s}}^{2}+9.77 \times 10^{3} C_{\mathrm{s}}+27\right) \times 10^{-6}+n_{0},
$$

where $n_{0}$ is the refractive index (1.3313) of pure water. The viscosity of an aqueous $\mathrm{NaCl}$ solution at $25^{\circ} \mathrm{C}$ can be expressed as follows: ${ }^{36}$

$$
\eta_{\mathrm{s}}=\left(1+0.0061 C_{\mathrm{s}}^{0.5}+0.0794 C_{\mathrm{s}}+0.01142 C_{\mathrm{s}}^{2}+6.19 \times 10^{-4} C_{\mathrm{s}}^{3.5}\right) \times \eta_{0} .
$$

Here, $\eta_{0}$ is the viscosity $\left(8.902 \times 10^{-3} \mathrm{~g} \mathrm{~cm}^{-1} \mathrm{~s}^{-1}\right)$ of pure water.

The specific refractive index increments $(\mathrm{dn} / \mathrm{dc})$ of free polymers in aqueous $\mathrm{NaCl}$ solutions for $C_{\mathrm{s}}$ from 0 to $5.0 \mathrm{M}$ were measured using a differential refractometer (Otsuka Electric DRM-1020, Osaka, Japan, $\lambda=633 \mathrm{~nm}$ ). The values of $\mathrm{dn} / \mathrm{dc}$ for free PMAPS $\left(\mathrm{M}_{\mathrm{w}}=1.36 \times 10^{5} \mathrm{~g} \mathrm{~mol}^{-1}, \mathrm{M}_{\mathrm{w}} / \mathrm{M}_{\mathrm{n}}=3.07\right)$ in aqueous $\mathrm{NaCl}$ solutions at $C_{\mathrm{s}}=0.050,0.10,0.50,1.0,3.0$ and $5.0 \mathrm{M}$ were determined to be $0.1347,0.1343,0.1300,0.1251,0.1124$ and $0.1023 \mathrm{~g}^{-1} \mathrm{~cm}^{3}$, respectively. The values of $\mathrm{dn} / \mathrm{dc}$ for free PMPC $\left(\mathrm{M}_{\mathrm{w}}=2.43 \times 10^{5} \mathrm{~g} \mathrm{~mol}^{-1}\right.$, $\left.\mathrm{M}_{\mathrm{w}} / \mathrm{M}_{\mathrm{n}}=8.90\right)$ in aqueous $\mathrm{NaCl}$ solutions at $C_{\mathrm{s}}=0,0.050,0.50,1.0,3.0$ and $5.0 \mathrm{M}$ were likewise determined to be $0.1415,0.1405,0.1363,0.1322,0.1190$ and $0.1038 \mathrm{~g}^{-1} \mathrm{~cm}^{3}$, respectively. The value of $\mathrm{dn} / \mathrm{dc}$ for free PMAPS in an aqueous $\mathrm{NaCl}$ solution at another unmeasured $C_{\mathrm{s}}$ was also determined to give the same $\mathrm{M}_{\mathrm{w}}$ of free PMAPS in an aqueous $\mathrm{NaCl}$ solution at $C_{\mathrm{s}}=0.10 \mathrm{M}$.

Small-angle X-ray scattering experiments of surface-grafted polymer chains on SiNPs in aqueous $\mathrm{NaCl}$ solutions at room temperature were carried out at the BL03XU ${ }^{37}$ beamline of SPring- 8 at an incident X-ray wavelength $\lambda$ of $0.1 \mathrm{~nm}$ with a sample-to-detector distance of $7994 \mathrm{~mm}$. The scattered intensity was detected using an imaging plate with $3000 \times 3000$ pixels over a scattering vector range from 0.02 to $0.6 \mathrm{~nm}^{-1}$. The scattering vector $(q)$ as defined by $4 \pi \sin (\theta) / \lambda$ was calibrated by the average of 6 peaks of dry collagen. The samples for SAXS measurements had four different concentrations $\left(C_{\mathrm{p}}=1.0\right.$ $2.0 \mathrm{mg} \mathrm{cm}^{-3}$ ) of SiNP-PMAPS and SiNP-PMPC in aqueous $\mathrm{NaCl}$ solutions $\left(C_{\mathrm{s}}=0-5.0 \mathrm{M}\right)$ contained in 2-mm diameter quartz capillaries.

Polymer solutions for scattering experiments were carefully prepared by a gravimetric method. After the free polymer and surface-grafted polymer on SiNPs were sufficiently dried under reduced pressure for $>24 \mathrm{~h}$ at $60^{\circ} \mathrm{C}$, the samples were dissolved in an aqueous $\mathrm{NaCl}$ solution at $40^{\circ} \mathrm{C}$ for $12 \mathrm{~h}$. The solutions of surface-grafted polymer on SiNPs were sonicated for $1 \mathrm{~h}$ to yield well-dispersed nanoparticle solutions. The resulting solutions were filtered with DISMIC filter units (polytetrafluoroethylene, PTFE, pore size of $0.45 \mu \mathrm{m}$ ) just before the measurements and poured directly into measurement cells in a clean bench. The weight fraction $\left(W_{\mathrm{p}}\right)$ was then converted to $C_{\mathrm{p}}\left(\mathrm{g} \mathrm{cm}^{-3}\right)$ by:

$$
C_{\mathrm{p}}\left(\mathrm{g} \mathrm{cm}^{-3}\right)=\frac{W_{\mathrm{p}}}{\rho_{\mathrm{s}}^{-1}\left(1-W_{\mathrm{p}}\right)+v_{\mathrm{p}} W_{\mathrm{p}}},
$$

where $\rho_{\mathrm{s}}$ and $v_{\mathrm{p}}$ are the densities of solvent and the partial specific volume of the polymer, respectively. The values of $v_{p}$ for free PMAPS in aqueous $\mathrm{NaCl}$ 
solutions at $C_{\mathrm{s}}=0.050,0.10,0.50,1.0,3.0$ and $5.0 \mathrm{M}$ were determined to be $0.690,0.688,0.682,0.678,0.697$ and $0.702 \mathrm{~cm}^{3} \mathrm{~g}^{-1}$, respectively. The values of $v_{\mathrm{p}}$ for free PMPC in the aqueous $\mathrm{NaCl}$ solutions at $C_{\mathrm{s}}=0,0.10,0.50,1.0,3.0$ and $5.0 \mathrm{M}$ were determined to be $0.729,0.742,0.759,0.763,0.762$ and $0.764 \mathrm{~cm}^{3} \mathrm{~g}^{-1}$, respectively.

Table 2 Results from SLS and DLS measurements of free PMAPS in aqueous $\mathrm{NaCl}$ solutions at $C_{\mathrm{s}}=0.050-5.0 \mathrm{~m}$

\begin{tabular}{lcccc}
\hline$C_{\mathrm{s}}(\mathrm{M})$ & $\begin{array}{c}A_{2} \times 10^{5} \\
\left(g^{-2} \mathrm{~cm}^{3} \mathrm{~mol}\right)\end{array}$ & $\begin{array}{c}D_{0} \times 10^{-7} \\
\left(\mathrm{~cm}^{2} \mathrm{~s}^{-1}\right)\end{array}$ & $R_{H}(\mathrm{~nm})$ & $\begin{array}{c}k_{D} \\
\left(g^{-1} \mathrm{~cm}^{3}\right)\end{array}$ \\
\hline 0.050 & -3.80 & 3.43 & 7.1 & -15.8 \\
0.065 & -1.18 & & & \\
0.074 & 0 & 3.36 & 7.2 & -9.4 \\
0.085 & 0.98 & & & \\
0.10 & 2.12 & 3.29 & 7.4 & -5.0 \\
0.50 & 10.8 & 2.85 & 8.2 & 9.5 \\
1.0 & 13.6 & 2.60 & 8.6 & 14.9 \\
3.0 & 16.0 & 1.97 & 9.0 & 20.6 \\
5.0 & 15.9 & 1.44 & 9.1 & 22.1 \\
\hline
\end{tabular}

Abbreviations: DLS, dynamic light scattering; PMAPS, poly[3-( $N$-2-methacryloyloxyethyl- $N, N$ dimethyl) ammonatopropanesulfonate]; SLS, static light scattering.

Table 3 Results from SLS and DLS measurements of free PMPC in aqueous $\mathrm{NaCl}$ solutions at $C_{\mathrm{s}}=0-5.0 \mathrm{~m}$

\begin{tabular}{lcccc}
\hline$C_{\mathrm{s}}(\mathrm{M})$ & $\begin{array}{c}\mathrm{A}_{2} \times 10^{4} \\
\left(g^{-2} \mathrm{~cm}^{3} \mathrm{~mol}\right)\end{array}$ & $\begin{array}{c}D_{0 \times 10^{-7}} \\
\left(\mathrm{~cm}^{2} \mathrm{~s}^{-1}\right)\end{array}$ & $R_{H}(\mathrm{~nm})$ & $\begin{array}{c}k_{D} \\
\left(g^{-1} \mathrm{~cm}^{3}\right)\end{array}$ \\
\hline 0 & 1.34 & 2.12 & 11.6 & 28.9 \\
0.050 & 1.60 & 2.11 & 11.6 & 29.6 \\
0.50 & 1.74 & 2.03 & 11.6 & 30.9 \\
1.0 & 1.87 & 1.99 & 11.3 & 25.9 \\
3.0 & 2.25 & 1.52 & 11.7 & 32.9 \\
5.0 & 2.32 & 1.14 & 11.5 & 30.5 \\
\hline
\end{tabular}

Abbreviations: DLS, dynamic light scattering; PMAPS, poly[3-( $N$-2-methacryloyloxyethyl- $N$, $\mathrm{N}$-dimethyl) ammonatopropanesulfonate]; SLS, static light scattering.

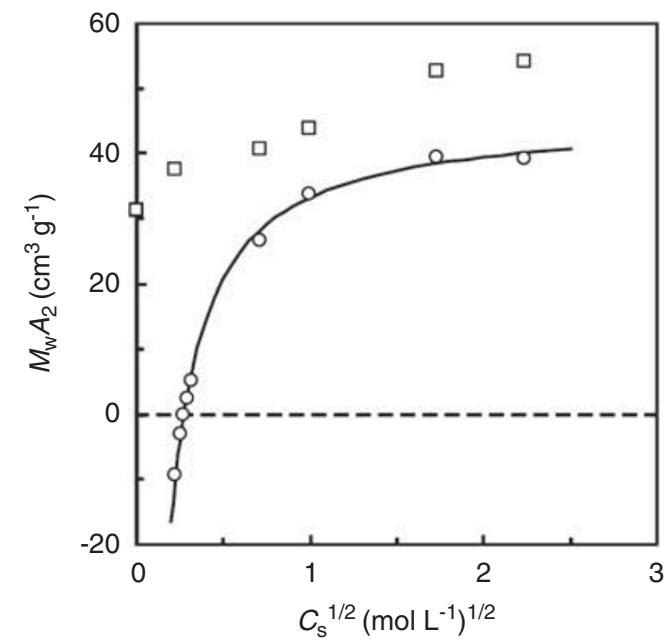

Figure 1 Dependence of $\mathrm{M}_{\mathrm{w}} A_{2}$ on $C_{\mathrm{s}}$ for free PMAPS $(O)$ and PMPC ( $\square$ ) in aqueous $\mathrm{NaCl}$ solutions. PMAPS, poly[3-( $N$-2-methacryloyloxyethyl- $\mathrm{N}, \mathrm{N}-$ dimethyl) ammonatopropanesulfonate]; PMPC, poly(2-methacryloyloxyethyl phosphorylcholine).

\section{RESULTS AND DISCUSSION}

Chain dimensional properties of free PMAPS and PMPC

The values of $A_{2}$ of free PMAPS and PMPC in aqueous $\mathrm{NaCl}$ solutions at $C_{\mathrm{s}}=0-5.0 \mathrm{M}$ are summarized in Tables 2 and 3. Details are described in the Supplementary Information. Figure 1 shows a $C_{\mathrm{s}}$ dependence of $\mathrm{M}_{\mathrm{w}} A_{2}$ for free PMAPS $(\bigcirc)$ and PMPC $(\square)$ in an aqueous $\mathrm{NaCl}$ solution at $25^{\circ} \mathrm{C}$. The $\mathrm{M}_{\mathrm{w}} A_{2}$ for PMPC gradually increased with increasing $C_{\mathrm{s}}$, whereas in the previous study, ${ }^{17}$ the same parameter was almost constant over the entire $C_{\mathrm{s}}$ region from 0 to $0.5 \mathrm{M}$ $\left(48.8 \mathrm{~cm} \mathrm{~g}^{-1}\right)$. It is possible that the small difference between our study and the previous one could be attributed to the MWD $\left(\mathrm{M}_{\mathrm{W}} /\right.$ $\mathrm{M}_{\mathrm{n}}=1.50$ ) of PMPC. However, the $\mathrm{M}_{\mathrm{w}} A_{2}$ for PMAPS increased sharply with increasing $C_{\mathrm{s}}$ in the $C_{\mathrm{s}}$ region below $0.5 \mathrm{M}$ and become almost constant in the higher $C_{\mathrm{s}}$ region $\sim 3.0 \mathrm{M}$. As $A_{2}$ reflects the volume exclusion of a polymer chain, Figure 1 suggests that the $C_{\mathrm{s}}$ dependence of the repulsive interaction between PMAPS chains in an aqueous $\mathrm{NaCl}$ solution is much stronger than that of PMPC. The value of $\mathrm{M}_{\mathrm{w}} A_{2}$ for PMAPS was observed to be 0 in an aqueous $\mathrm{NaCl}$ solution at $C_{s}=0.074 \mathrm{M}$. Therefore, we defined an aqueous $\mathrm{NaCl}$ solution at $C_{\mathrm{s}}=0.074 \mathrm{M}$ as the $\theta$-concentration $\left(C_{\mathrm{s}, \theta}\right)$ of PMAPS. Kato et al. ${ }^{28}$ previously found using SLS that the $C_{s, \theta}$ was $0.060 \mathrm{M}$ for PMAPS at $30^{\circ} \mathrm{C}$ is an aqueous $\mathrm{NaCl}$ solution. It is possible that the small difference between $C_{\mathrm{s}, \theta}=0.074 \mathrm{~m}$ in our study and $C_{\mathrm{s}, \theta}=0.060 \mathrm{M}$ in the previous study could be attributed to the MWD of PMAPS and the experimental temperature.

The values of the diffusion coefficient at an infinite dilution $\left(D_{0}\right)$, the hydrodynamic radius $\left(R_{\mathrm{H}}\right)$ and the concentration coefficient of the diffusion coefficient $\left(k_{\mathrm{D}}\right)$ of free PMAPS and PMPC in aqueous $\mathrm{NaCl}$ solutions at $C_{s}=0-5.0 \mathrm{M}$ are summarized in Tables 2 and 3. Details are described in the Supplementary Information. Figure 2 shows the $C_{\mathrm{s}}$ dependence of $R_{\mathrm{H}}$ for free PMAPS $(\bigcirc)$ and PMPC $(\square)$ in aqueous $\mathrm{NaCl}$ solutions at $25^{\circ} \mathrm{C}$. The $R_{\mathrm{H}}$ of PMPC was almost constant regardless of $C_{s}$, whereas the $R_{\mathrm{H}}$ for PMAPS increased with increasing $C_{s}$. The $R_{\mathrm{H}}$ values of PMPC in aqueous $\mathrm{NaCl}$ solutions were larger than those of PMAPS at all $C_{\mathrm{s}}$, despite that the weight average degree of polymerization $\left(N_{\mathrm{w}}=792\right)$ of PMPC is less than that of PMAPS $\left(N_{\mathrm{w}}=884\right)$. Considering that the $R_{\mathrm{H}}$ reflects the hydrodynamic dimen-

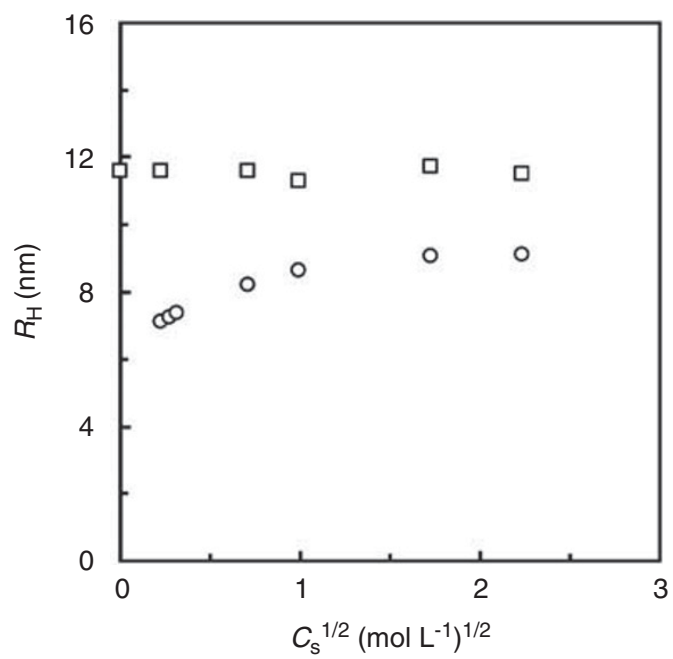

Figure 2 Dependence of $R_{\mathrm{H}}$ on $C_{\mathrm{S}}$ for free PMAPS ( $O$ ) and PMPC ( $\square$ ) in aqueous $\mathrm{NaCl}$ solutions. PMAPS, poly[3-( $N$-2-methacryloyloxyethyl- $N, N$ dimethyl) ammonatopropanesulfonate]; PMPC, poly(2-methacryloyloxyethyl phosphorylcholine). 


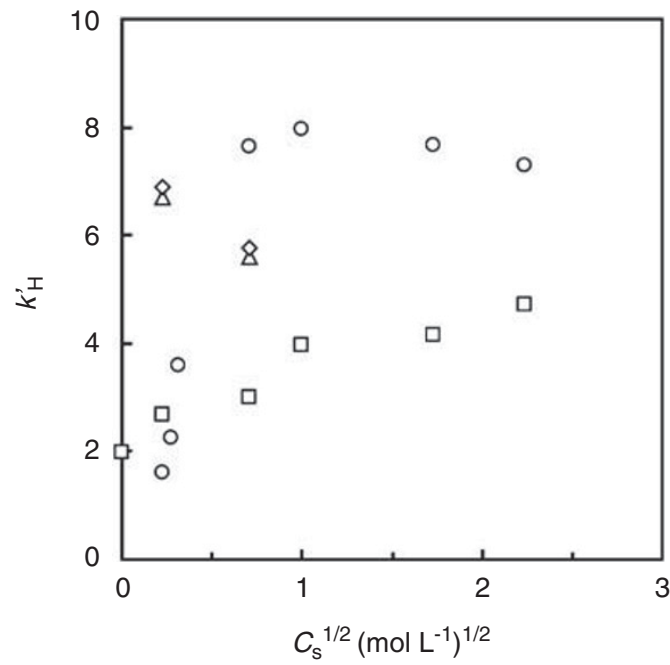

Figure 3 Dependence of $K_{\mathrm{H}}$ on $C_{\mathrm{S}}$ for free PMAPS $(O)$ and PMPC ( $\square$ ) in aqueous $\mathrm{NaCl}$ solutions, together with that of free $\mathrm{NaPSS}^{41}(\triangle)$ and NaPAMPS ${ }^{42,43}(\diamond)$ with the same molecular weight. PMAPS, poly[3-(N-2methacryloyloxyethyl- $\mathrm{N}, \mathrm{N}$-dimethyl) ammonatopropanesulfonate]; PMPC, poly(2-methacryloyloxyethyl phosphorylcholine).

sions of a polymer chain, the larger $R_{\mathrm{H}}$ of PMPC implies that the main chain stiffness of PMPC is higher than that of PMAPS in the solution.

The value of $k_{\mathrm{D}}$ for flexible polymer chains is defined by the following equation: ${ }^{38}$

$$
k_{\mathrm{D}}=2 A_{2} \mathrm{M}_{\mathrm{w}}-v_{\mathrm{p}}-k_{\mathrm{H}}^{\prime}\left(\frac{4 \pi R_{\mathrm{H}}^{3}}{3}\right)\left(\frac{N_{\mathrm{A}}}{\mathrm{M}_{\mathrm{w}}}\right),
$$

where $k_{\mathrm{H}}^{\prime}$ is a universal constant for free chains irrespective of the kind of polymers and molecular weight. The value of $k_{H}^{\prime}$ for typical flexible polymers in a good solvent was reported over a range from 4 to $6 .{ }^{38}$ The value of $k_{\mathrm{H}}^{\prime}$ calculated from the literature data ${ }^{39,40}$ for atactic poly(methyl methacrylate) in acetonitrile at $44.0{ }^{\circ} \mathrm{C}$ ( $\theta$-solvent) is estimated to be approximately 1.3-1.8. The values of $k_{\mathrm{H}}^{\prime}$ for free PMAPS and PMPC were calculated from equation (6) using the measured values of $A_{2}, \mathrm{M}_{\mathrm{w}}, v_{\mathrm{p}}, k_{\mathrm{D}}$ and $R_{\mathrm{H}}$. Figure 3 shows the $C_{\mathrm{s}}$ dependence of $k_{\mathrm{H}}^{\prime}$ for free PMAPS $(\bigcirc)$ and PMPC $(\square)$ in aqueous $\mathrm{NaCl}$ solutions at $25^{\circ} \mathrm{C}$, together with that of free poly(styrene sulfonate sodium salt) (NaPSS; $\left.\mathrm{M}_{\mathrm{w}}=2.56 \times 10^{5} \mathrm{~g} \mathrm{~mol}^{-1}\right)^{41}(\Delta)$ and poly(2-acrylamido-2-methylpropanesulfonate sodium salt) (NaPAMPS; $\left.\mathrm{M}_{\mathrm{w}}=2.76 \times 10^{5} \mathrm{~g} \mathrm{~mol}^{-1}\right)^{42,43}(\diamond)$ with the same molecular weight. The values of $k_{\mathrm{H}}^{\prime}$ for PMAPS and PMPC in aqueous $\mathrm{NaCl}$ solutions were revealed to be $1.5-8$, which may be regarded as a $\theta$-state and a good solvent state, indicating the reduction in intramolecular and intermolecular interaction between polymer chains with increasing $C_{s}$. However, $k_{\mathrm{H}}^{\prime}$ of the typical polyanions, such as NaPSS, NaPAMPS and sodium carboxylmethyl cellose, ${ }^{44}$ apparently decreased with increasing $C_{\text {s }}$ until eventually reaching a $\theta$-state and poor solvent state because the intramolecular and intermolecular repulsive interactions between polymer chains were screened by hydrated ions.

\section{Characterization of SiNP-PMAPS and SiNP-PMPC}

The scattering form factor $(P(q)$, which is related to $\Delta I(q) / \Delta I(0)$ $(\Delta \mathrm{I}(q)$ is the experimental excess scattering intensity) from the SAXS data for SiNP-BHE in TFE, may be compared with the solid sphere model with polydispersity. According to Aragón and Pecora, ${ }^{45}$ the scattering function $\left(P_{\mathrm{z}}(q \bar{R})\right)$ for the assumed Schulz-distributed solid spheres with a radius of $R$ is expressed by

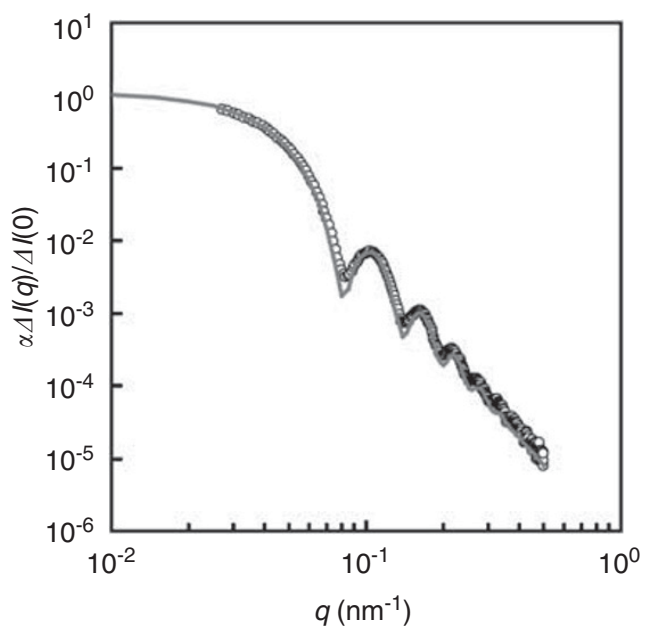

Figure 4 SAXS profiles of SiNP-BHE in TFE. The solid curves represent the theoretical values for the assumed Schulz-distributed spherical particles with a radius of $R=55.0 \mathrm{~nm}$ and an exponential parameter of $z=180$. SAXS, small-angle X-ray scattering; SiNP-BHE, immobilization of (2-bromo-2-methyl)propionyloxyhexyltriethoxysilane on a SiNP; TFE, 2,2,2trifluoroethanol.

$$
P_{\mathrm{z}}(q \bar{R})=\int_{0}^{\infty} \frac{\alpha^{2}(R)\left\{\frac{3}{(q R)^{3}}[\sin (q R)-q R \cos (q R)]\right\}^{2}}{\alpha_{\mathrm{z}}^{2}(\bar{R})} f_{\mathrm{z}}(R) d R
$$

and

$$
f_{\mathrm{z}}(R)=\frac{1}{z !}\left(\frac{z+1}{\bar{R}}\right)^{z+1} R^{z} \exp \left[-\frac{(z+1) R}{\bar{R}}\right],
$$

where $\alpha(R), f_{\mathrm{z}}(R), z$ and $\bar{R}$ are the polarizability of the particle, the Schulz distribution function, the width of the distribution and the average radius of the sphere, respectively. $\alpha(R)$ depends on the size through the bulk volume of the particle. Polydispersity $(p)$ for a Schulz distribution can be written as $p^{2}=1 /(z+1)$. The experimental data for SiNP-BHE $\left(C=1.38 \mathrm{mg} \mathrm{cm}^{-3}\right)$, which were used for preparation of SiNP-PMAPS, can be described assuming Schulz-distributed spherical particles with a radius of $R=55.0 \mathrm{~nm}$ and an exponential parameter of $z=180$, corresponding to a polydispersity of $p=0.074$, as shown in Figure 4. These values of SiNP-BHE used SiNP-PMPC were determined by the same method to be $R=56.0 \mathrm{~nm}, z=180$ and $p=0.074$.

The graft density of a polymer brush on the SiNP surface is expressed by

$$
\sigma=\frac{R \rho_{\text {silica }} N_{\mathrm{A}}}{3 \mathrm{M}_{\mathrm{n}}\left(\frac{1}{w}-1\right)}
$$

where $\rho_{\text {silica }}, w$ and $N_{\mathrm{A}}$ are the density of silica $\left(1.6 \mathrm{~g} \mathrm{~cm}^{-3}\right)$, the weight loss of a polymer and Avogadro's number, respectively. The graft densities of PMAPS and PMPC brushes on a SiNP surface were calculated using equation (9) to be 0.129 and 0.065 chains per $\mathrm{nm}^{2}$, respectively. The average numbers of graft PMAPS and PMPC chains per SiNP were estimated to be 4910 and 2590 chains, respectively, assuming the aforementioned graft density and the SiNP surface area. These values of SiNP-PMAPS and SiNP-PMPC are summarized in Table 1.

Dimensions of grafted chains of PMAPS and PMPC on SiNP The typical autocorrelation function $\left(g^{2}(t)-1\right)$ and relaxation spectrum $(A(\tau))$ measured by DLS for SiNP-PMAPS in an aqueous $\mathrm{NaCl}$ 


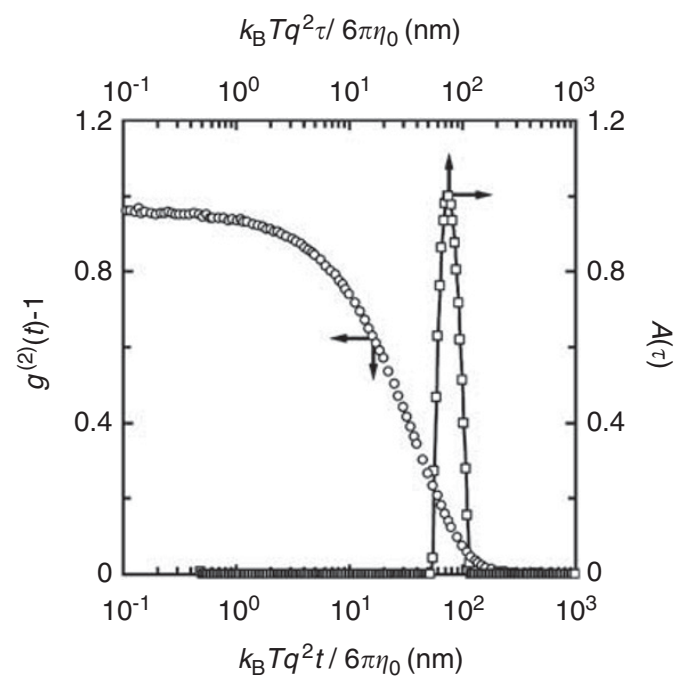

Figure 5 Typical autocorrelation function $(O)$ obtained by DLS for SiNPPMAPS and relaxation spectrum $(\square)$ calculated from the autocorrelation function. The concentration of SiNP-PMAPS in an aqueous $\mathrm{NaCl}$ solution at $C_{\mathrm{s}}=5.0 \mathrm{M}$ and the scattering angle are $C_{\mathrm{p}}=0.47 \mathrm{mg} \mathrm{cm}^{-3}$ and $\theta=90^{\circ}$. DLS, dynamic light scattering; SiNP-PMAPS, silica nanoparticles immobilized with poly[3-( $N$-2-methacryloyloxyethyl- $N, N$-dimethyl) ammonatopropanesulfonate].

Table 4 Results from DLS and SAXS measurements of SiNP-PMAPS in aqueous $\mathrm{NaCl}$ solutions at $C_{\mathrm{s}}=0.050-5.0 \mathrm{M}$

\begin{tabular}{lccccc}
\hline$C_{\mathrm{s}}(\mathrm{M})$ & $D_{0} \times 10^{-8}\left(\mathrm{~cm}^{2} \mathrm{~s}^{-1}\right)$ & $R_{H, \text { brush }}(\mathrm{nm})$ & $s(\mathrm{~nm})$ & $v_{\text {brush }}\left(g^{-1} \mathrm{~cm}^{3}\right)$ & $\rho$ \\
\hline 0.050 & 3.31 & 9.4 & 9.5 & 0.69 & 1.01 \\
0.10 & 3.43 & 8.0 & 10 & 0.69 & 1.25 \\
0.50 & 3.35 & 7.5 & 17 & 0.68 & 2.27 \\
1.0 & 3.17 & 7.7 & 18 & 0.68 & 2.33 \\
3.0 & 2.54 & 7.5 & 19 & 0.70 & 2.52 \\
5.0 & 1.84 & 8.1 & 21 & 0.74 & 2.59
\end{tabular}

Abbreviations: DLS, dynamic light scattering; PMAPS, poly[3-( $N$-2-methacryloyloxyethyl- $N, N$ dimethyl) ammonatopropanesulfonate]; SAXS, small-angle X-ray scattering; SiNP, silica nanoparticle.

Table 5 Results from DLS and SAXS measurements of SiNP-PMPC in aqueous $\mathrm{NaCl}$ solutions at $C_{\mathrm{s}}=0-5.0 \mathrm{M}$

\begin{tabular}{lccccc}
\hline$C_{\mathrm{s}}(\mathrm{M})$ & $D_{\mathrm{O}} \times 10^{-8}\left(\mathrm{~cm}^{2} \mathrm{~s}^{-1}\right)$ & $R_{H, \text { brush }}(\mathrm{nm})$ & $s(\mathrm{~nm})$ & $v_{\text {brush }}\left(\mathrm{g}^{-1} \mathrm{~cm}^{3}\right)$ & $\rho$ \\
\hline 0 & 3.45 & 7.5 & 9.5 & 0.73 & 1.26 \\
0.050 & 3.40 & 7.8 & 9.5 & 0.74 & 1.21 \\
0.50 & 3.29 & 7.6 & 9.5 & 0.76 & 1.25 \\
1.0 & 3.11 & 8.0 & 9.5 & 0.76 & 1.19 \\
3.0 & 2.51 & 7.5 & 9.5 & 0.76 & 1.26 \\
5.0 & 1.83 & 7.7 & 9.5 & 0.86 & 1.23 \\
\hline
\end{tabular}

Abbreviations: DLS, dynamic light scattering; PMAPS, poly[3-( $N$-2-methacryloyloxyethyl- $N, N$ dimethyl) ammonatopropanesulfonate]; SAXS, small-angle X-ray scattering; SiNP, silica nanoparticle.

solution at $C_{\mathrm{s}}=5.0$ are shown in Figure 5. The concentration of SiNPPMAPS and the scattering angle were $C=0.47 \mathrm{mg} \mathrm{cm}^{-3}$ and $\theta=90^{\circ}$, respectively. $A(\tau)$ at the relaxation time $(\tau)$ was calculated from the intensity of $\mathrm{g}^{2}(t)-1$ at time $(t)$ by a CONTIN analysis. ${ }^{46,47} A(\tau)$ was observed as a single sharp peak. $A(\tau)$ of all concentrations and scattering angles for SiNP-PMAPS and SiNP-PMPC solutions showed a unimodal distribution and sharp peak, indicating the homogenous dispersion of SiNP-PMAPS and SiNP-PMPC in aqueous $\mathrm{NaCl}$ solutions at various $C_{\mathrm{s}}$ without any aggregations. By extrapolating to $q=0$ and $C=0$, the values of $D_{0}$ and $R_{\mathrm{H}}$ for SiNP-PMAPS in an aqueous $\mathrm{NaCl}$ solution at $C_{\mathrm{s}}=5.0 \mathrm{M}$ were determined to be $1.84 \times 10^{-8} \mathrm{~cm}^{2} \mathrm{~s}^{-1}$ and $71.2 \mathrm{~nm}$, respectively. The values of $D_{0}$ and $R_{\mathrm{H}}$ for SiNP-PMAPS and SiNP-PMPC in aqueous $\mathrm{NaCl}$ solutions at each $C_{\mathrm{s}}$ were also determined using the same method. The values of $D_{0}$ and the hydrodynamic radius of a polymer layer $\left(R_{\mathrm{H} \text {,brush }}\right)$ calculated from $\left(R_{\mathrm{H}}-R_{\mathrm{c}}\right) / 2$ are summarized in Tables 4 and 5 .

Figure 6a shows the SAXS profiles for SiNP-PMAPS in aqueous $\mathrm{NaCl}$ solutions for $C_{\mathrm{s}}$ over a range from 0.050 to $5.0 \mathrm{M}$. The SAXS profiles showed smooth minima in the SiNP-PMAPS form factor, which was slightly shifted to a low- $q$ region, unlike the SiNP-BHE form factor. SiNP-PMAPS in an aqueous $\mathrm{NaCl}$ solution is expected to form a coreshell structure, as shown in the inset of Figure 6a. Here, we estimated the radius of gyration of the polymer layer of SiNP-PMAPS from the SAXS profile using a core-shell model analysis, taking the interacting excluded-volume chains into consideration. The scattering form factor for the core-shell model contains four terms as shown below: ${ }^{48}$

$$
P(q)=\left\{\begin{array}{l}
N^{2} \Delta Z_{\mathrm{e}, \text { core }}^{2} P_{\text {core }}(q)+N \Delta Z_{\mathrm{e}, \text { chain }}^{2} P^{\prime}(q) \\
+2 N \Delta Z_{\mathrm{e}, \text { core }} \Delta Z_{\mathrm{e}, \text { chain }} S_{\text {core-chain }}(q) \\
+N\left[N-P^{\prime}(0)\right] \Delta Z_{\mathrm{e}, \text { chain }}^{2} A_{\text {chain }}^{2}(q)
\end{array}\right\} N^{-2}\left(\Delta Z_{\mathrm{e}, \text { core }}+\Delta Z_{\mathrm{e}, \text { chain }}\right)^{-2},
$$

where $N$ is the number of surface-grafted polymer chains on SiNP, $\Delta Z_{\mathrm{e}}$ the excess electron density, $P_{\text {core }}(q)$ a scattering function for a rigid sphere assuming Schulz distribution calculated from equations (7) and (8), $P^{\prime}(q)$ the effective form factor of a chain in the corona chains expressed by the following equations (11) and (12), $S_{\text {core-chain }}(q)$ the structure factor between the core and corona chains expressed by equations (13) and (14) and $A_{\text {chain }}(q)$ the form-factor amplitude of the chain expressed by equation (14).

$$
P^{\prime}(q)=\frac{P_{\mathrm{PWC}}(q)}{1+v P_{\mathrm{PWC}}(q)}
$$

and

$$
v=1.4\left[\frac{N s^{2}}{4\left(R_{\mathrm{c}}+s\right)^{2}}\right]^{1.04},
$$

where $P_{\mathrm{PWC}}(q), v$ and $s$ are the scattering functions for an infinitely thin perturbed wormlike chain, ${ }^{49}$ parameter-related surface coverage of chains and radius of gyration of the polymer layer, respectively.

$$
S_{\text {core-chain }}(q)=\frac{3}{\left(q R_{\mathrm{c}}\right)^{3}}\left[\sin \left(q R_{\mathrm{c}}\right)-q R \cos \left(q R_{\mathrm{c}}\right)\right] A_{\text {chain }}(q)
$$

and

$$
A_{\text {chain }}(q)=\frac{\int Z_{\text {chain }}(r) r^{2} \frac{\sin (q r)}{q r} \mathrm{~d} r}{\int Z_{\text {chain }}(r) r^{2} \mathrm{~d} r},
$$

where $R_{\mathrm{c}}$ and $Z_{\text {chain }}(r)$ are the core radius and the average radial electron density profile of the corona chains, respectively.

The excess electron density of the core $\left(\Delta Z_{\mathrm{e}, \text { core }}\right)$ and chain $\left(\Delta Z_{\text {e,chain }}\right)$ are defined as

$$
\Delta Z_{\mathrm{e}, \text { core }}=N_{\mathrm{A}} \rho_{\text {silica }} \frac{n_{\mathrm{e}, \text { silica }}}{M_{\text {silica }}}-N_{\mathrm{A}} \rho_{\text {brush }} \frac{n_{\mathrm{e}, \text { brush }}}{M_{0, \text { brush }}}
$$

and

$$
\Delta Z_{\mathrm{e}, \text { chain }}=N_{\mathrm{A}} \rho_{\text {brush }} \frac{n_{\mathrm{e}, \text { brush }}}{M_{0, \text { brush }}}-N_{\mathrm{A}} \rho_{\mathrm{s}} \frac{n_{\mathrm{e}, \mathrm{s}}}{M_{\mathrm{s}}}
$$



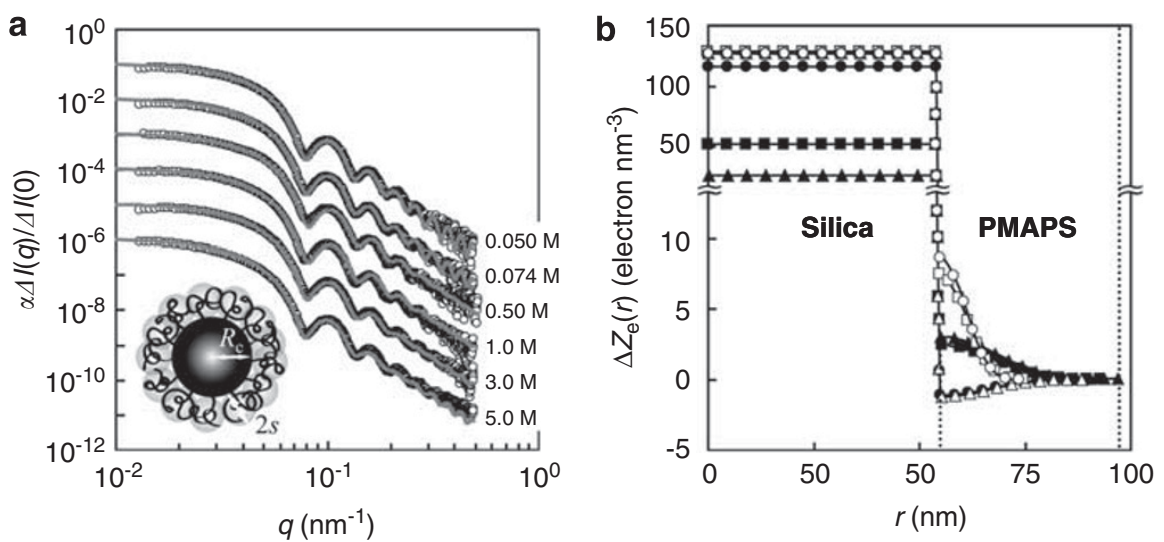

Figure 6 (a) SAXS profiles of SiNP-PMAPS in aqueous $\mathrm{NaCl}$ solutions at $C_{\mathrm{s}}$ over a range from 0 to $5.0 \mathrm{~m}$. The solid curves represent the values calculated from equations (7), (8) and (10)-(17) with the two model parameters. (b) Radial electron density profiles for SiNP-PMAPS in aqueous NaCl solutions at $C_{\mathrm{s}}=0.050(\bigcirc), 0.074(\square), 0.50(\triangle), 1.0(\bullet), 3.0(\square)$ and $5.0(\mathbf{\Delta}) \mathrm{M}$ estimated from the SAXS profile using a core-shell model analysis. SAXS, smallangle X-ray scattering; SiNP-PMAPS, silica nanoparticles immobilized with poly[3-( $\mathrm{N}$-2-methacryloyloxyethyl- $N, N$-dimethyl) ammonatopropanesulfonate].
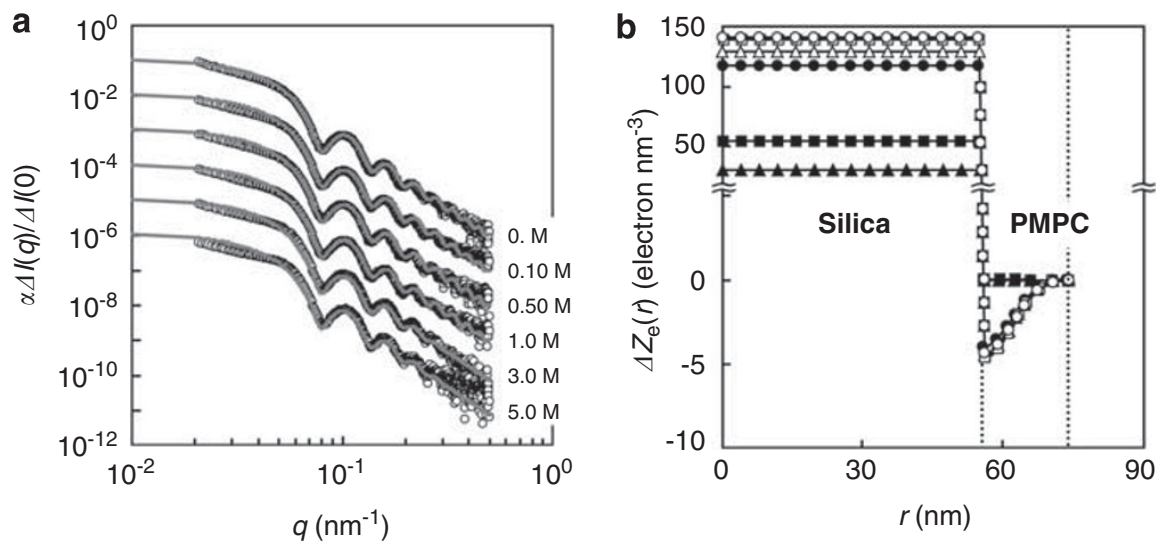

Figure 7 (a) SAXS profiles of SiNP-PMPC in the aqueous $\mathrm{NaCl}$ solutions at $C_{\mathrm{S}}$ over a range from 0 to $5.0 \mathrm{~m}$. The solid curves represent the values calculated from equations (7), (8) and (10)-(17) with the two model parameters. (b) Radial electron density profiles for SiNP-PMPC in aqueous NaCl solutions at $C_{\mathrm{s}}=0$ $(0), 0.050(\square), 0.50(\triangle), 1.0(\bullet), 3.0(\square)$ and $5.0(\mathbf{\Delta})$ M estimated from SAXS profile using a core-shell model analysis. SAXS, small-angle X-ray scattering; SiNP-PMAPS, silica nanoparticles immobilized with poly[3-( $N$-2-methacryloyloxyethyl- $N, N$-dimethyl) ammonatopropanesulfonate].

where $n_{\mathrm{e}, \mathrm{core}}$ and $M_{\text {silica }}$ are the number of electrons and the molecular weight of the silica, respectively, whereas $n_{\mathrm{e}, \text { brush }}$ and $M_{0, \text { brush }}$ are the number of electrons and the molecular weight per repeating unit of the polymer brush, respectively. The density of the polymer brush in the solvent $\left(\rho_{\text {brush }}\right)$ is defined as $\left(1-v_{\text {brush }} \rho_{\mathrm{s}}\right) C_{\text {brush }}+\rho_{\mathrm{s}}$, where the $v_{\text {brush }}$ is the partial specific volume of the polymer brush, which was determined by fitting the experimental data of the SAXS profile with equations (7), (8) and (10)-(17) in the low- $q$ region. However, the accurate concentration of the polymer brush $\left(C_{\text {brush }}\right)$ has a distribution along with the distance from the nanoparticle surface to the outer solvent phase due to the swollen brush structure. Therefore, here we used the apparent concentration of the polymer brush in the solvent, $C_{\text {brush,app }}$ instead of $C_{\text {brush }}$, by calculation using the following expression:

$$
C_{\text {brush,app }}=\frac{3 M_{n, \text { brush }} N}{4 \pi N_{\mathrm{A}}\left[\left(2 s+R_{\text {core }}\right)^{3}-R_{\text {core }}^{3}\right]} .
$$

The experimental SAXS profile for SiNP-PMAPS in an aqueous $\mathrm{NaCl}$ solution at $C_{\mathrm{s}}=0.050 \mathrm{M}$ was close to the theoretical profile obtained from equations (7), (8) and (10)-(17) for a core radius $R_{\mathrm{c}}=55.0 \mathrm{~nm}$, core polydispersity $p=0.074$, polymer layer radius $s=9.5 \mathrm{~nm}$ and $v_{\text {brush }}=0.69 \mathrm{~g}^{-1} \mathrm{~cm}^{3}$ as shown in the Figure $6 \mathrm{a}$. The values of $s$ and v brush for SiNP-PMAPS in aqueous $\mathrm{NaCl}$ solutions at various $C_{\mathrm{s}}$ values were also estimated using the same method, and these values are listed in Table 4. The solid lines in Figure 6a are values calculated from equations (7), (8) and (10)-(17) with the two model parameters. The value of $v_{\text {brush }}$ was close to that of $v_{p}$ of the free PMAPS in an aqueous $\mathrm{NaCl}$ solution at a given $C_{s}$. The experimental SAXS profiles for SiNP-PMAPS in aqueous $\mathrm{NaCl}$ solutions at all $C_{\mathrm{S}}$ values were close to the profiles calculated from equations (7), (8) and (10)-(17) with the two model parameters. Figure $6 \mathrm{~b}$ shows the radial profiles for SiNPPMAPS in aqueous $\mathrm{NaCl}$ solutions at various $C_{\mathrm{s}}$ values estimated from the SAXS profile base on the core-shell model incorporated with interaction among the surface-grafted perturbed wormlike chains, which are the so-called interacting self-avoiding chains. ${ }^{48}$

Figure 7a shows the SAXS profiles for SiNP-PMPC in aqueous $\mathrm{NaCl}$ solutions at $C_{\mathrm{s}}$ values over a range from 0 to $5.0 \mathrm{M}$. The characteristic parameters of the SiNP-PMPC in aqueous $\mathrm{NaCl}$ solutions at various $C_{\mathrm{s}}$ estimated by the procedure mentioned above are summarized in Table 5. The solid lines in Figure $7 \mathrm{a}$ are the theoretical curves calculated from equations (7), (8) and (10)-(17) with a core radius of $R_{\mathrm{c}}=56.0 \mathrm{~nm}$, core polydispersity of $p=0.074$ and the model para- 


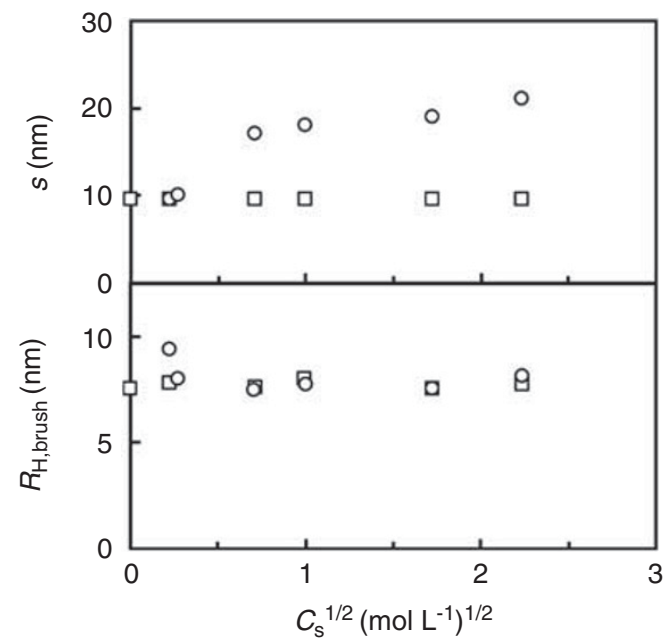

Figure 8 Dependence of $s$ and $R_{\mathrm{H}, \text { brush }}$ on $\mathrm{NaCl}$ concentration for SiNPPMAPS $(O)$ and SiNP-PMPC $(\square)$ in aqueous $\mathrm{NaCl}$ solutions at $C_{\mathrm{s}}$ in the range $0-5.0 \mathrm{~m}$. SiNP-PMAPS, silica nanoparticles immobilized with poly[3( $\mathrm{N}$-2-methacryloyloxyethyl- $\mathrm{N}, \mathrm{N}$-dimethyl) ammonatopropanesulfonate].

meters listed in Table 5. The scattering factor for SiNP-PMPC in aqueous $\mathrm{NaCl}$ solutions is described by the core-shell model, taking into account the interacting self-avoiding chains and assuming a Schulz-distributed core with two fitting parameters. The value of $v_{\text {brush }}$ is close to that of $v_{p}$ of free PMPC in aqueous $\mathrm{NaCl}$ solutions for a given $C_{\mathrm{s}}$, except for $C_{\mathrm{s}}=5.0 \mathrm{M}$. Figure $7 \mathrm{~b}$ illustrates the radial profiles for SiNP-PMPC in aqueous $\mathrm{NaCl}$ solutions at various $C_{\mathrm{s}}$ values estimated from the SAXS profile and the core-shell model containing the interacting self-avoiding chains.

Figure 8 shows the $C_{\mathrm{s}}$-dependence of $R_{\mathrm{H} \text {,brush }}$ and $s$ for SiNPPMAPS $(\bigcirc)$ and SiNP-PMPC $(\square)$ in aqueous $\mathrm{NaCl}$ solutions. The $R_{\mathrm{H} \text {,brush }}$ and $s$ for SiNP-PMPC were constant over the entire $C_{\mathrm{s}}$ region from 0 to $5.0 \mathrm{M}$. The $C_{\mathrm{s}}$ dependence of $R_{\mathrm{H} \text {,brush }}$ for SiNP-PMPC is in good agreement with that reported by Matsuda et al., who also did not observe a swelling of the PMPC brush upon addition of up to $0.5 \mathrm{M}$ NaCl. ${ }^{17}$ These results imply that $C_{\mathrm{s}}$ dependence of the repulsive interaction between polymer chains for SiNP-PMPC in an aqueous $\mathrm{NaCl}$ solution is similar to that of the free PMPC. However, the value of $s$ for SiNP-PMAPS increased with increasing $C_{\mathrm{s}}$, whereas $R_{\mathrm{H} \text {,brush }}$ for SiNP-PMAPS slightly decreased with increasing $C_{\mathrm{s}}$ in the $C_{\mathrm{s}}$ region below $0.5 \mathrm{M}$, and that parameter become almost constant in the $C_{\mathrm{S}}$ region above $0.5 \mathrm{M}$. Polzer et al. ${ }^{16}$ reported that the $R_{\mathrm{H}}$ of PMAPS brush shell on a colloidal particle consisting of a divinylbenzene crosslinked polystyrene core (PS-co-DVB/PMAPS) was almost constant in the $C_{\mathrm{s}}$ region below $0.5 \mathrm{M}$, but increased with increasing $C_{\mathrm{s}}$ in the $C_{\mathrm{s}}$ region above $0.5 \mathrm{~m}^{16}$ The $R_{\mathrm{H} \text {,brush }}(7.7 \mathrm{~nm})$ of the PMAPS brush for SiNP-PMAPS in an aqueous $\mathrm{NaCl}$ solution at $C_{\mathrm{s}}=1.0 \mathrm{M}$ was larger than that $(4.0 \mathrm{~nm})$ of the PMAPS brush shell in the previous report at the same $C_{\mathrm{s}}$, despite that the $\mathrm{M}_{\mathrm{w}}\left(3.02 \times 10^{4} \mathrm{~g} \mathrm{~mol}^{-1}\right)$ of the surfacegrafted PMAPS chains in our study was smaller than that $\left(\mathrm{M}_{\mathrm{w}}=6.96 \times 10^{4} \mathrm{~g} \mathrm{~mol}^{-1}\right)$ of the previous study. It is possible that the difference in the chain dimension of the PMAPS brush between SiNP-PMAPS $\left(\sigma=0.129\right.$ chains per $\left.\mathrm{nm}^{2}\right)$ and PS-co-DVB/PMAPS $\left(\sigma=0.08\right.$ chains per $\left.\mathrm{nm}^{2}\right)$ can be attributed to graft density. These results imply that the $C_{\mathrm{s}}$ dependence of the repulsive interaction between polymer chains for SiNP-PMAPS in an aqueous $\mathrm{NaCl}$ solution is similar to that of the PMAPS brush shell for PS-co-DVB/

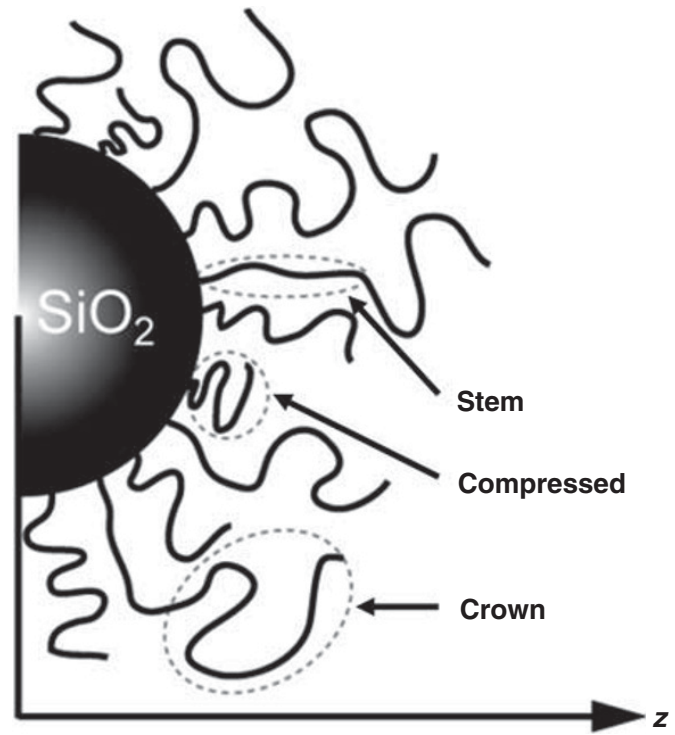

Figure 9 Schematic cross-sectional view of the internal structure of surface-grafted polymer chains with polydispersity on SiNPs. SiNP, silica nanoparticle.

PMAPS and the free PMAPS, except for the $C_{\mathrm{s}}$-dependence of $R_{\mathrm{H} \text {,brush }}$ for SiNP-PMAPS.

The $\mathrm{M}_{\mathrm{W}}$ dependence of the $z$-average, mean-square radius of gyration $\left(\left\langle S^{2}\right\rangle_{\mathrm{z}}\right)$ for the free PMAPS in a $\theta$-state in an aqueous $\mathrm{NaCl}$ solution at $0.074 \mathrm{M}$ is given by ${ }^{12}$

$$
\left\langle S^{2}\right\rangle_{\mathrm{z}}^{1 / 2}=0.018 M_{\mathrm{w}}^{0.5}
$$

The thickness of the polymer brush layer for SiNP-PMAPS was estimated to be $9.5 \mathrm{~nm}$, which was much larger than the $\left\langle S^{2}\right\rangle_{\mathrm{z}}^{1 / 2}=$ $3.1 \mathrm{~nm}$ calculated from equation (18) for free PMAPS chains with the same $C_{\mathrm{s}}$ and $\mathrm{M}_{\mathrm{w}}$. The chain dimensions of the polymer brush for SiNP-PMAPS in an aqueous solution were actually larger than the free PMAPS. It is well known that polymer chains in concentrated polymer brushes are extended because of the excluded-volume effect of neighboring polymer chains. ${ }^{10}$ Thus, significant change seems to have occurred in the chain conformation between the brush and the free polymer.

It is well known that $\rho$, defined as the ratio of the radius of gyration to the hydrodynamic radius, is a universal constant for free chains almost irrespective of the chemical structure and molecular weight of polymers. The values of $\rho$ estimated from $s$ measured by SAXS and $R_{\mathrm{H} \text {,brush }}$ measured by DLS of the polymer layer for SiNP-PMAPS and SiNP-PMPC in aqueous $\mathrm{NaCl}$ solutions at all $C_{\mathrm{S}}$ are summarized in Tables 4 and 5. The value of $\rho$ for SiNP-PMPC in aqueous $\mathrm{NaCl}$ solutions at all $C_{\mathrm{s}}$ was approximately constant (1.19-1.26) and was similar to those of typical flexible polymers in $\theta$-solvent and good solvents (1.2-1.5). ${ }^{50}$ The $\rho$ for SiNP-PMAPS increased with increasing $C_{\mathrm{s}}$ in the $C_{\mathrm{s}}$ region below $0.5 \mathrm{~m}$ and became almost constant in the $C_{\mathrm{s}}$ region above $0.5 \mathrm{M}$. The values (2.27-2.59) of $\rho$ for SiNP-PMAPS in the $C_{\mathrm{s}}$ region above $0.5 \mathrm{M}$ were larger than those of reference data for PMAPS in an aqueous $\mathrm{NaCl}$ solution for $C_{\mathrm{s}}$ in the range $0.06-1.0 \mathrm{M}$ at $30{ }^{\circ} \mathrm{C}(1.1-1.3)^{28}$ and the Gaussian chain limit (1.48)..$^{50}$ Thus, the chain conformation of PMAPS and PMPC brushes on the SiNP surface behaves like a semi-flexible and flexible polymer chain, respectively. It is possible that the difference in the chain conformation between PMAPS and PMPC brushes could be attributed to the broad 
MWD and low graft density of PMPC because of the following reasons.

de Vos et al. ${ }^{14}$ reported that the internal structure of the polymer brush by numerical self-consistent field theory is strongly influenced by polydispersity, as shown in Figure 9. Short chains are compressed close to the grafting interface, whereas long chains have a characteristic flower-like conformation. These long chains stretch strongly (forming a stem) when surrounded by shorter chains and decrease their stretching (forming a crown) when only surrounded by longer chains. These findings imply that chain conformation of the PMPC brush with a broad MWD on a SiNP surface behaves like a Gaussian coil. Therefore, our report may be the first experimental report on the crucial difference in the chain conformation between the brush on a SiNP and the free PMAPS with salt concentration dependence.

\section{CONCLUSIONS}

We performed SLS, DLS and SAXS for PMAPS and PMPC in aqueous $\mathrm{NaCl}$ solutions and found that PMPC had a relatively stiff structure in an aqueous $\mathrm{NaCl}$ solution for a wide range of $C_{\mathrm{s}}(0-5.0 \mathrm{M})$, unlike PMAPS. This is because the $R_{\mathrm{H}}$ of PMPC in aqueous $\mathrm{NaCl}$ solutions was larger than that of the PMAPS, whereas the weight average degree of polymerization $\left(N_{\mathrm{w}}=792\right)$ of PMPC was less than that of PMAPS $\left(N_{\mathrm{w}}=884\right)$. The $k_{\mathrm{H}}^{\prime}$ values of both PMAPS and PMPC in aqueous $\mathrm{NaCl}$ solutions were higher than 1.5 in all $C_{\mathrm{s}}$ regions, indicating that the polymers were in the $\theta$-state or good solvent state. The scattering factors for SiNP-PMAPS and SiNP-PMPC in aqueous $\mathrm{NaCl}$ solutions at $C_{\mathrm{s}}=0-5.0 \mathrm{M}$ were well described by the core-shell model, taking into account interacting self-avoiding chains and assuming a Schulz-distributed core with two fitting parameters. From the ratio of the radius of gyration measured by SAXS to the hydrodynamic radius measured by DLS for the polymer layer for SiNP-PMAPS and SiNP-PMPC in aqueous $\mathrm{NaCl}$ solutions at $C_{\mathrm{s}}=0-5.0 \mathrm{M}$, the chain conformations of PMAPS and PMPC brushes on a silica surface resembled semi-flexible and flexible polymer chains, respectively.

\section{ACKNOWLEDGEMENTS}

We thank Nissan Chemical Industries for kindly giving us the silica nanoparticles used in this study. The synchrotron radiation experiments were performed at BL03XU in the SPring-8 facility with the approval of the Japan Synchrotron Radiation Institute (JASRI) (Proposal No. 2010A 7239). We sincerely appreciate Professor Hiroshi Jinnai of JST, ERATO Takahara soft interfaces project for many valuable comments.

1 Morishima, Y. Amphiphilic polyelectrolytes: characterization of associative properties and self-assembled nanostructures in water in 'Polyelectrolytes and Polyzwitterions' (eds Lowe, A. B. \& McCormic C. L.) pp 19-46 (Oxford University Press, New York, 2006).

2 Schulz, D. N., Peiffer, D. G., Agarwal, P. K., Larabee, J., Kaladas, J. J., Soni, L., Handwerker, B. \& Garner, R. T. Phase behaviour and solution properties of sulphobetaine polymers. Polymer 27, 1734-1742 (1986).

3 Cheng, N., Brown, A. A., Azzaroni, O. \& Huck, W. T. S. Thickness-dependent properties of polyzwitterionic brushes. Macromolecules 41, 6317-6321 (2008).

4 Chen, M., Briscoe, W. H., Armes, S. P. \& Klein, J. Lubrication at physiological pressures by polyzwitterionic brushes. Science 323, 1698-1701 (2009).

5 Kobayashi, M., Terayama, Y., Hosaka, N., Kaido, M., Suzuki, A., Yamada, N., Torikai, N., Ishihara, K. \& Takahara, A. Friction behavior of high-density poly(2-methacryloyloxyethylphosphorylcholine) brush in aqueous media. Soft Matter 3, 740-746 (2007)

6 Ishihara, K., Ueda, T. \& Nakabayashi, N. Preparation of phospholipid polymers and their properties as polymer hydrogel membranes. Polym. J. 22, 355-360 (1990)

7 Ishihara, K., Nomura, H., Mihara, T., Kurita, K., Iwasaki, Y. \& Nakabayashi, N. Why do phospholipid polymers reduce protein adsorption? J. Biomed. Mater. Res. 39, 323-330 (1998).

8 Ishihara, K., Oshida, H., Endo, Y., Ueda, T., Watanabe, A. \& Nakabayashi, N. Hemocompatibility of human whole blood on polymers with a phospholipid polar group and its mechanism. J. Biomed. Mater. Res. 26, 1543-1552 (1992)
9 Tsujii, Y., Ohno, K., Yamamoto, S., Goto, A. \& Fukuda, T. Structure and properties of high-density polymer brushes prepared by surface-initiated living radical polymerization. Adv. Polym. Sci. 197, 1-45 (2006).

10 Yamamoto, S., Ejaz, M., Tsujii, Y., Matsumoto, M. \& Fukuda, T. Surface interaction forces of well-defined, high-density polymer brushes studied by atomic force microscopy. 1. Effect of chain length. Macromolecules 33, 5602-5607 (2000).

11 Terayama, Y., Kikuchi, M., Kobayashi, M., Hino, M. \& Takahara, A. Influence of salt concentration on swelling states of poly(sulfobetaine) brush at aqueous interface. J. Phys. Conf. Ser. 184, 012011 (2009).

12 Terayama, Y., Arita, H., Ishikawa, T., Kikuchi, M., Mitamura, K., Kobayashi, M., Yamada, N. L. \& Takahara, A. Chain dimensions in free and immobilized brush states of polysulfobetaine in aqueous solution at various salt concentrations. J. Phys. Conf. Ser. 272, 012010 (2011).

13 Kobayashi, M., Mitamura, K., Terada, M., Yamada, N. L. \& Takahara, A. Characterization of swollen states of polyelectrolyte brushes in salt solution by neutron reflectivity. J. Phys. Conf. Ser. 272, 012019 (2011).

14 de Vos, W. M. \& Leermakers, F. A. M. Modeling the structure of a polydisperse polymer brush. Polymer 50, 305-316 (2009).

15 Guo, C. \& Ballauff, M. Spatial dimensions of colloidal polyelectrolyte brushes as determined by dynamic light scattering. Langmuir 16, 8719-8726 (2000).

16 Polzer, F., Heigl, J., Schneider, C., Ballauff, M. \& Borisov, O. V. Synthesis and analysis of zwitterionic spherical polyelectrolyte brushes in aqueous solution. Macromolecules 44, 1654-1660 (2011).

17 Matsuda, Y., Kobayashi, M., Annaka, M., Ishihara, K. \& Takahara, A. Dimensions of a free linear polymer and polymer immobilized on silica nanoparticles of a zwitterionic polymer in aqueous solutions with various ionic strengths. Langmuir $\mathbf{2 4 ,} \mathbf{8 7 7 2 - 8 7 7 8}$ (2008).

18 Matsuda, Y., Kobayashi, M., Annaka, M., Ishihara, K. \& Takahara, A. Dimension of poly(2-methacryloyloxyethyl phosphorylcholine) in aqueous solutions with various ionic strength. Chem. Lett. 35, 1310-1311 (2006).

19 Salamone, J. C., Volksen, W., Olson, A. P. \& Israel, S. C. Aqueous solution properties of a poly(vinyl imidazolium sulphobetaine). Polymer 19, 1157-1162 (1978).

20 Monroy Soto, V. M. \& Galin, J. C. Poly(sulphopropylbetaines): 2. Dilute solution properties. Polymer 25, 254-262 (1984).

21 Huglin, M. B. \& Rego, J. M. Influence of a salt on some properties of hydrophilic methacrylate hydrogels. Macromolecules 24, 2556-2563 (1991).

22 Huglin, M. B. \& Radwan, M. A. Properties of poly[ $N$-2-(methyacryloyloxy)ethyl $-N, N$ dimethyl- $N$-3-sulfopropylammonium betaine] in dilute solution. Makromol. Chem. 192, 2433-2445 (1991)

23 Wielema, T. A. \& Engberts, J.B.F.N. Zwitterionic polymers I. synthesis of a novel series of poly(vinylsulphobetaines). effect of structure of polymer on solubility in water. Eur. Polym. J. 23, 947-950 (1987).

24 Salamone, J. C., Volksen, W., Israel, S. C., Olson, A. P. \& Raia, D. C. Preparation of inner salt polymers from vinylimidazolium sulphobetaines. Polymer 18, 1058-1062 (1977).

25 Liaw, D.- J., Lee, W.- F., Whung, Y.- C. \& Lin, M.- E. Aqueous solution properties of poly[3-dimethyl(methacryloyloxyethyl)ammonium propane sulfonate]. J. Appl. Polym. Sci. 34, 999-1011 (1987).

26 Monroy Soto, V. M. \& Galin, J. C. Poly(sulfopropylbetaines): I. Synthesis and characterization. Polymer 25, 121-128 (1984).

27 Huglin, M. B. \& Radwan, M. A. Unperturbed dimensions of a zwitterionic polymethacrylate. Polym. Int. 26, 97-104 (1991).

28 Kato, T. \& Takahashi, A. Excluded volume effects of sulphobetaine polymers. Ber. Bunsenges. Phys Chem. 100, 784-787 (1996).

29 Duann, Y.- F., Chen, Y.- C., Shen, J.- T. \& Lin, Y.- H. Thermal induced graft polymerization using peroxide onto polypropylene fiber. Polymer 45, 6839-6843 (2004).

30 Queffelec, J., Gaynor, S. G. \& Matyjaszewski, K. Optimization of atom transfer radical polymerization using $\mathrm{Cu}(\mathrm{I})$ /tris(2-(dimethylamino)ethyl)amine as a catalyst. Macromolecules 33, 8629-8639 (2000).

31 Ohno, K., Morinaga, T., Koh, K., Tsujii, Y. \& Fukuda, T. Synthesis of monodisperse silica particles coated with well-defined, high-density polymer brushes by surface-initiated atom transfer radical polymerization. Macromolecules 38, 2137-2142 (2005).

32 Kobayashi, M. \& Takahara, A. Synthesis and frictional properties of poly(2,3-dihydroxypropyl methacrylate) brush prepared by surface-initiated atom transfer radical polymerization. Chem. Lett. 34, 1582-1583 (2005).

33 Terayama, Y., Kikuchi, M., Kobayashi, M. \& Takahara, A. Well-defined poly(sulfobetaine) brushes prepared by surface-initiated ATRP using a fluoroalcohol and ionic liquids as the solvents. Macromolecules 44, 104-111 (2011).

34 Pike, E. R., Pomeroy, W. R. M. \& Vaughan, J. M. Measurement of Rayleigh ratio for several pure liquids using a laser and monitored photon counting. J. Chem. Phys. 62, 3188-3192 (1975).

35 Jákli, G.Y. The $\mathrm{H}_{2} \mathrm{O}-\mathrm{D}_{2} \mathrm{O}$ solvent isotope effects on the molar volumes of alkali-chloride solutions at $T=(288.15,298.15$, and 308.15) K. J. Chem. Thermodyn. 39, 1589-1600 (2007).

36 Hai-Lang, Z. \& Shi-Jun, H. Viscosity and density of water + sodium chloride + potassium chloride solutions at 298.15 K. J. Chem. Eng. Data 41, 516-520 (1996).

37 Masunaga, H., Ogawa, H., Takano, T., Sasaki, S., Goto, S., Tanaka, T., Seike, T., Takahashi, S., Takeshita, K., Nariyama, N., Ohashi, H., Ohata, T., Furukawa, Y., Matsushita, T., Ishizawa, Y., Yagi, N., Takata, M., Kitamura, H., Sakurai, K., Tashiro, K., Takahara, A., Amamiya, Y., Horie, K., Takenaka, M., Kanaya, T., Jinnai, H., Okuda, H. Akiba, I. Takahashi, I., Yamamoto, K. Hikosaka, M. Sakurai, S., Shinohara, Y., Okada, A. \& Sugihara, Y. Multipurpose soft-material SAXS/WAXS/GISAXS beamline at SPring-8. Polym. J. 43, 471-477 (2011). 
38 Matsuda, Y., Nojima, R., Sato, T. \& Watanabe, H. Reversed micelle of polybutadiene living anions in cyclohexane. Macromolecules 40, 1631-1637 (2007).

39 Tamai, Y., Konishi, T., Einaga, Y., Fujii, M. \& Yamakawa, H. Mean-square radius of gyration of oligo- and poly(methyl methacrylate)s in dilute solution. Macromolecules 23, 4067-4075 (1990).

40 Arai, T., Sawatari, N., Yoshizaki, T., Einaga, Y. \& Yamakawa, H. Excluded-volume effects on the hydrodynamic radius of atactic and isotactic oligo- and poly(methyl methacrylate)s in dilute solution. Macromolecules 29, 2309-2314 (1996).

41 Yashiro, J. \& Norisuye, T. Excluded-volume effects on the chain dimensions and transport coefficients of sodium poly(styrene sulfonate) in aqueous sodium chloride. J. Polym. Sci. B Polym. Phys. 40, 2728-2735 (2002).

42 Yashiro, J., Hagino, R., Sato, S. \& Norisuye, T. Chain stiffness and excludedvolume effects in polyelectrolyte solutions: characterization of sodium poly(2-acrylamido-2-methylpropanesulfonate) in aqueous sodium chloride. Polym. J. 38, 57-63 (2006).

43 Yashiro, J. \& Norisuye, T. Translational diffusion coefficient of sodium poly(2-acrylamido-2-methylpropanesulfonate) in aqueous sodium chloride. Polym. Bull. 56, 467-474 (2006).
44 Sakurada, I. \& Nakashima, T. Concerning the influence of the electrical on the viscosity of hydrophilic colloids. Colloid Polym. Sci. 66, 62-67 (1934).

45 Aragón, S. R. \& Pecora, R. Theory of dynamic light scattering from polydisperse systems. J. Chem. Phys. 64, 2395-2404 (1976).

46 Provencher, S. W. A constrained regularization method for inverting data represented by linear algebraic or integral equations. Comput. Phys. Commun. 27, 213-227 (1982).

47 Provencher, S. W. CONTIN: a general purpose constrained regularization program for inverting noisy linear algebraic and integral equations. Comput. Phys. Commun. 27, 229-242 (1982).

48 Pedersen, J. S., Svaneborg, C., Almdal, K., Hamley, I. W. \& Young, R. N. A small-angle neutron and X-ray contrast variation scattering study of the structure of block copolymer micelles: corona shape and excluded volume interactions. Macromolecules 36, 416-433 (2003).

49 Nakamura, Y. \& Norisuye, T. Scattering function for wormlike chains with finite thickness. J. Polym. Sci. B. Polym. Phys. 42, 1398-1407 (2004).

50 Konishi, T., Yoshizaki, T. \& Yamakawa, H. On the 'universal constants' $\rho$ and $\Phi$ of flexible polymers. Macromolecules 24, 5614-5622 (1991).

Supplementary Information accompanies the paper on Polymer Journal website (http://www.nature.com/pj) 